\title{
Needle Stick Injuries: A Study Among Health Care Workers in Tertiary Care Centre Nepal
}

\section{Manjari Bajracharya and Sushila Bhandari}

Department of Nursing, Nepalese Army Institute of Health Sciences, Shree Birendra Hospital, Chhauni, Kathmandu, Nepal

\section{ABSTRACT}

Introduction: A needle stick injury is a percutaneous piercing wound typically set by a needle point but possibly also by other sharp instruments or objects commonly encountered by health care professionals because of the risk to transmitting blood borne diseases like Hepatitis B Virus (HBV), Hepatitis C (HCV) and Human Immuno Deficiency Virus (HIV). The aim of this study was to assess the prevalence, causes, awareness and knowledge regarding Needle Stick Injury among health care workers Tertiary Care Centre of Nepal.

Methods: A descriptive cross sectional study was conducted in 350 staffs of Tertiary Care Centre Nepal, from June to August 2013. Data was collected through semi-structured self-administered questionnaire. All the collected data was processed and analyzed by using descriptive statistics namely the frequency and percentage.

Results: The study showed that out of the 350 respondents, $65.1 \%$ had there medicinal years of practices extended to five years. Among the responses $44.8 \%$ mentioned, highest number of needle prick was observed when recapping the needles due to long working hours. About $64.6 \%$ respondents washed their hands with soap, water or other antiseptics for effective post exposure preventive measures and $24.9 \%$ had access to infection control protocol.

Conclusions: Despite the awareness regarding needle stick injury and its preventive measures, health care workers are yet bound to face it often during their surgical or medicinal area of practice due to monotonous and long working hours.

Keywords: Awareness, Health Care Workers, Knowledge, Needle Stick Injuries

Correspondence: Manjari Bajracharya, Department of Nursing, Nepalese Army Institute of Health Sciences, Shree Birendra Hospital, Chhauni, Kathmandu, Nepal. Email: mbajracharya123@gmail.com

DOI: http://dx.doi.org/10.3126/mjsbh.v17i1.18871

Submitted on: 2018-01-01

Accepted on: 2018-02-28 


\section{INTRODUCTION}

Needle Stick Injury (NSI) is a percutaneous piercing wound typically set by a needle point, but possibly also by other sharp instruments or objects, commonly encountered by people handling needles in the medical settings. Needle stick injury is occupational hazards in the medical areas. ${ }^{1}$

NSI means the par literal introduction into the body of the healthcare worker during the performance of his or her duties, of blood other potentially infectious material by a hollow bone needle or sharp instrument, including, but not limited to needles, lancets, scalpels, and contaminated broken glass. $^{2}$

Needle stick injury is a common event in the health care environment when drawing blood, administering intramuscular or intravenous drugs, or performing other procedures involving sharp instruments, the needle can slip and injure the health care worker. This sets the stage to transmit viruses from the same person to the recipient. These injuries also commonly occur during needle recapping and as a result of fracture to place used needle in approved sharps containers. ${ }^{1}$

Generally NSI cause only minor bleeding or visible trauma, however in the absence of bleeding the risk of viral infection remains. A NSI may also pose a risk for patients if the injured health care worker

Table 1. Responses of health care workers elements related to standard precautions

\begin{tabular}{|l|r|r|}
\hline Observance of needle prick & Frequency & $\%$ \\
\hline $\begin{array}{l}\text { Injecting medicine/ } \\
\text { drawing blood }\end{array}$ & 122 & 34.9 \\
\hline Recapping of Needle & 115 & 32.9 \\
\hline $\begin{array}{l}\text { Surgery suturing } \\
\text { Handling uncooperative } \\
\text { patient }\end{array}$ & 44 & 12.6 \\
\hline
\end{tabular}

carries HBV, HCV or HIV. NSI are not limited to medical community. Any environment where sharps are encountered, poses a risk. ${ }^{1}$

\section{METHODS}

This was a descriptive, cross sectional study conducted during the months of June to August, 2013 in all OPDs and wards of a Tertiary Care Centre, Nepal. Out of 1204 staffs of this center only 350 were selected for this study. The data collection was done by using the close ended questionnaires. The purpose of the research was to obtain quantitative data on NSI. After data collection, it was compiled and analyzed using SPSS version 17.4 .

\section{RESULTS}

Out of the 350 respondents, $51.7 \%$ were males and $48.3 \%$ were females, $48.6 \%$ were involved in medical area whereas $49.1 \%$ to surgical area of practice. Likewise, $40.6 \%$ of the respondents were registered nurses and the nursing assistant constituted $59.4 \%$ of the respondents. $34.9 \%$ of respondents had less than five years of practice, while $65.1 \%$ have practice of more than five years. $88.3 \%$ respondents have had at least one NSI, whereas $11.7 \%$ respondents have no experience of any NSIs. Among the responses $43.1 \%$ respondents had multiple NSIs that is more than two times, where as $44.9 \%$ had less than or equals to two times multiple NSIs. During observation 34.9\% were needle pricked while injecting medicine or

Table 2. Reason of needle prick

\begin{tabular}{|l|r|r|}
\hline Characteristics & Frequency & $\%$ \\
\hline Long working hours & 156 & 44.8 \\
\hline Inappropriate Environment & 105 & 30 \\
\hline Stress & 26 & 7.4 \\
\hline Inappropriate Training & 23 & 6.6 \\
\hline
\end{tabular}


Table 3. Post exposure preventive measures

\begin{tabular}{|l|r|r|}
\hline Characteristics & Frequency & $\%$ \\
\hline $\begin{array}{l}\text { Know about patient's } \\
\text { disease }\end{array}$ & 52 & 14.9 \\
\hline Allow injury to bleed & 26 & 7.4 \\
\hline $\begin{array}{l}\text { Wash with soap, water and } \\
\text { antiseptic }\end{array}$ & 226 & 64.6 \\
\hline $\begin{array}{l}\text { Notify infectious control } \\
\text { person }\end{array}$ & 6 & 1.7 \\
\hline
\end{tabular}

drawing blood. According to the responses reason behind needle prick was due to long working that is $44.8 \%$, followed by $30 \%$ inappropriate environment, $7.4 \%$ due to stress and the least that is $6.6 \%$ was because of inappropriate training. In terms of post exposure preventive measures, $14.9 \%$ knew about patients' disease, $\quad 7.4 \%$ allowed injuries to bleed, $64.6 \%$ washed hands with soap, water or antiseptics and $1.7 \%$ notified infectious control person. Regarding years of experiences $65.5 \%$ of the respondents have more than 5 years of experiences.

\section{DISCUSSION}

In this study majority $(88.3 \%)$ of respondents were exposure to NSIs which is similar to the studies carried out in other hospital reveals the incidence of NSIs is around $88.2 \%(\mathrm{~N}=350) .{ }^{9}$ Other study conducted in Delhi also similar to this study which reveals $79.5 \%$ of HCWs reported having had one or more NSIs in their career. ${ }^{13}$ Various other studies in Nepal, among health care workers from tertiary care hospital and a study from rural north has shown similar results to the present study i.e. $70.8 \%$ and $73 \%$ respectively .4

Long working hours is apparently seems to be the main cause of NSIs among the respondents i.e. $44.8 \%$. Because of long duty hours staffs became fatigue and cause NSIs. This finding is supported
Table 4. Years of Experiences

\begin{tabular}{|l|r|r|}
\multicolumn{1}{|c|}{ Years } & Frequency & $\%$ \\
\hline$<5$ years & 122 & $34.8 \%$ \\
\hline$>$ 5 years & 228 & $65.2 \%$ \\
\hline
\end{tabular}

by study done in Delhi, which shows $50.4 \%$ of NSI occurs due to fatigue. ${ }^{14}$

The study shows that $64.6 \%$ of the respondents washed the site of injury with soap and water as preventive measure. Previous studies too have shown a similar results i.e. $60.9 \%$ had washed the site of injury with water and soap. ${ }^{13}$

The health care worker who had work experience of five or more than five years were exposed to needle stick injuries than those who had work experience of less than five years. The most common belief is that as the work experience increases the chances of the exposure to needle stick injuries will be decreased, this study is supported by the study done at Egypt and Malaysia. ${ }^{11,12 .}$

\section{CONCLUSIONS}

The occurrence of NSI was found to be quite common in all categories of health personnel as well as found more in those who are work for long hours. Avoidable practices like recapping of needles were contributing to the injuries. Registered nurses are more aware and more precautions then nursing assistants for injecting, drawing blood and in other procedures to use needles. Prevention of NSI is an integral part of prevention programs in the work place, and training of HCWs regarding safety practices are essentially need to be an ongoing activity at a hospital. 
To cite this article: Bajracharya M, Bhandari S. Needle Stick Injuries: A study among health care workers Tertiary Care Centre Nepal. MJSBH. 2018;17(1):44-8.

Conflict of Interest: None declared

\section{REFERENCES}

1. https://en.wikipedia.org/wiki/Needlestick_injury.Retrived on June 2016.

2. Bandolier Extra- Evidence Based Health Care. Needle Stick Injuries, 2003, pp. 1-17, www.bandolier.org.uk/Extraforbando/needle.pdf.

3. Afridi, kumar, Sayani. Neddle stick Injuries-Risk and preventive Factors: A Study among Health care workers in tertiary care Hospital in Pakistan,2013.

DOI: $10.5539 /$ gjhs.v5n4p85.

4. Gurung N, Paudel K, Pun CB. Needle Stick injuries among health care workers in Tertiary care Teaching hospital, Pokhara Nepal, Journal of GMC -Nepal 2010.

PMID 20418554

5. Students of Nepalese Army Institute of Health Sciences College of Nursing, in Service Education, Needle Stick Injury 2014.

6. Medical Devices Agency, Safe use \& disposal of sharps. 2001

7. Adefolalu A. Needle Stick Injuries and Health Workers: A Preventable Menace, Annals of Medical and Health Sciences, 2014; 4.

DOI: $10.4103 / 2141-9248.138046$

8. Research. 2014; 4(2), 159-160.

DOI: $10.4103 / 2141-9248.138046$

9. Holla R, Unnikrishnan B. Occupational Exposure to Needle Stick Injuries Among Health Care Personnel in a Tertiary Care Hospital: A cross sectional study. March 19, 2014.

DOI: doi.org/10.4172/2161-0711.S2-004

10. Sayami M, Tamrakar J. Needle Stick Injuries Among Health Care Professionals in Tertiary Hospital T.U Teaching Hospital Kathmandu Nepal. Journal of T.U December 2013.

DOI:646-642-1-PB.pdf.

11. Center for Disease Control and Prevention, Recommendations for Post-exposure Prophylaxis (PeP) for exposure to HBV, HCV and HIV, MMWR2001;50:22

DOI: https://www.cdc.gov/mmwr/preview/mmwrhtml/rr5011a1.htm

12. Nili T, Amal MS, Shaul SS. The Health Beliefs of Hospital Staff and the Reporting of Needle Stick Injury. JaclinNurs. 2006;15:1228-39

DOI: $10.1111 / j .1365-2702.2006 .01423 . x$ 
13. Siddique K, Mirza SH, Tauqir SF, Anwar I, Malik AZ. Knowledge Attitude and Practices Regarding Needle Stick Injuries amongst Health Care Providers. Pakistan J Surg, 2008, 24(4) 243-248 DOI: 12230-50125-1-PB.pdf.

14. Sharma,R, Rasania NK, Verma A, Singh S. Study of Prevalence and Response to Needle Stick Injuries among Health Care Workers in a Tertiary Care Hospital in Delhi, India. Indian Journal of Community medicine, 2010;35(1), 74-77

DOI: $10.4103 / 0970-0218.62565$ 